\title{
A Study on Peach Blooms Painted With Blood From the Perspective of Foreignization
}

\author{
Shaohui Lu \\ School of Foreign Language, Zunyi Medical University, Zunyi, China
}

\begin{abstract}
This research analyzes the drama, Peach Blooms Painted with Blood, as translated by Xu Yuanchong in light of Lawrence Venuti's foreignization translation theory. The four elements influencing the foreignization translation method: purpose of the translator, type of text, poetics, and ideology are introduced, defined, analyzed, and illustrated in the translations by employing foreignization translation in linguistic, religious, and sociocultural contexts based on the five cultural contexts put forward by Eugene A. Nida. Following discussion of Nida's contexts, the cases are analyzed through comparison and contrast of the connotations, implications, and situations existing between Chinese and Western cultures with the aim of enhancing the understanding of classical Chinese poetry and prose, thus enabling translators to interpret and advance Chinese classical works in a more effective way.
\end{abstract}

Index Terms - foreignization, influential elements, cultural contexts

\section{INTRODUCTION}

Lawrence Venuti's (1995) proposal of the domesticating method and the foreignizing method caused an enduring and profound argument among the schools of translation theory. As he put it, "foreignizing translation is based on the assumption that literacy is not universal, that communication is complicated by cultural differences between and within linguistic communities. But foreignizing is also an attempt to recognize and allow those differences to shape cultural discourses in the target language" (Venuti, 2004, p.146). The "foreign" in foreignizing translations was realized as a resistance to academic literary values so as to embrace rather than exclude popular forms affiliated with various social groups. In recognizing the cultural value ignored by many dominant cultures, foreignizing translation revises the traditional concepts of orthodox.

Foreignizing translation can be seen as a resistancy to the dominant cultural viewpoints. Although this resistance deviates from the original text to some degree, it causes a radical rethinking towards the fidelity of translation, termed "abusive" by Philip Lewis. Venuti depicts it this way, "the translator whose aim is to recreate analogically the abuse that occurs in the original text winds up both forcing the linguistic and conceptual system of which [the translation] is a dependent and directing a critical thrust back toward the text that it translates" (Venuti, 2004, p.291). Some scholars criticize foreignizing translation for its influency, while not realizing it is the discontinuity and indeterminacy that are faithful to the original text. This is because some foreign works are obscure or hard to understand, so the translator chooses the strategy of discontinuity or indeterminacy to highlight that feature of the original text. As different languages have different rules to standardize their sentences, style, or manner of writing, the discontinuity or indeterminacy appears if the faithful translated versions are to be faithful to the author's intent.

\section{A. Research Background}

After the foreignization method was proposed, there are heated discussions at home and abroad. In 2011, "Post-modern Translation Studies: the Lawrence Venuti's Translation Theory Case" was chosen as a general project in the field of Humanities and Social Sciences researched by the Ministry of Education, from which, it can thus be seen, that, though many domestic scholars had already taken part in the research of Venuti's translation theory after its introduction in Guo Jianzhong's (1998) article The Cultural Factors in Translation-Domestication and Foreignization, it was still a hot and worthwhile topic of study. This theory has been used by numerous academic articles to analyze various works. For our generation, carrying forward Chinese traditional culture to the world is a noble mission. Drama is an essential part of Chinese culture; but in comparison to fiction and poetry translation, drama translation has garnered less attention. The translation field has paid less heed to the study of drama, which reflects a lack of proper focus, especially in China. The study of drama translation is treated as only translating literary works, rather than building a complete theoretical system of drama translation. Meanwhile, the number of translated works from other languages into Chinese is much larger than that of Chinese works to other languages, which is not beneficial to the spread Chinese culture. As to transmitting Chinese culture to foreigners, foreignization is quite a good way to realize it. Under these circumstances, the author chooses this topic to do a research in order to make a contribution to drama translation study and carry forward Chinese culture. Using foreignization translation of Chinese drama is an effective tool for sharing, understanding and appreciation of Chinese culture with the world. 
The main focus of this paper is to employ the foreignization theory to analyze Peach Blooms Painted with Blood, translated by $\mathrm{Xu}$ Yuanchong. It is found that the translator's intention, text type, the poetics of the original work, as well as the ideology affect the foreignizing translation. This paper will also analyze Xu's translated version from the perspective of cultural contexts, including the contexts of linguistic culture, religious culture, and social culture. Some examples of foreignizing translation under each cultural context will be illustrated and analyzed. Two key points will be addressed. One is the advantages of foreignizing translation in the Peach Blooms Painted with Blood; the other is why the adaptation of foreignization will become a trend in Chinese drama translation.

\section{Research Methods}

After careful review of the relevant literature and sources on the results of previous studies of foreignizing translation theory, Chinese drama translation, Kunqu Opera translation as well as Peach Blooms Painted with Blood, has earned the author a familiarity with the relevant issues involved. The author will now define the relevant terminology and then read and analyze the translated version carefully to gather a large number of examples, from which some representative ones to be analyzed will be chosen in order to support the author's point of view.

\section{The Significance of Research}

On one hand, the study of foreignization translation theory has been in full swing. With the acceleration of globalization, people's tolerance toward foreign cultures is constantly increasing, together with an increasing enthusiasm for study of foreignization translation theory. In 2008, Lawrence Venuti published a highly controversial book, the second edition of The Translators Invisibility, in which he clarified some key terms and ideas, and through new research further elucidated some arguments undoubtedly providing more hypotheses or ways for the research of foreignization translation theory. Through the author's study and research, it gives a clearer and systematic understanding of foreignization translation theory to readers.

On the other hand, while there has been a large number of texts translated into the Chinese language, translation of Chinese works into other languages, particularly widely-used English, is urgently needed. Having the works translated into English will reveal more of China to the world. Peach Blooms Painted with Blood is one of the valuable masterpieces of China's traditional culture. However, its English version has seldom been researched at home and abroad. This author will explore and summarize this work of the drama translation, demonstrating that foreignizing translation is an effective strategy. It is also aimed at offering guidance and assistance to the reader's translation practice. What's more, the author would like to make a contribution to promulgating Chinese traditional culture.

\section{Overview of Xu's Translated Work PEACH BLOOMS PAINTED With BLOOD}

Early in September, 2009, Peach Blooms Painted with Blood translated by Xu Yuanchong and his son, Frank M. Xu, was published, followed by de luxe edition in January, 2012.

In Peach Blooms Painted with Blood, Xu Yuanchong and Frank M. Xu chose five acts of the original work to translate: "Beauty and Duty", "Word and Sword", "Crime and Succession", "Persecution on Persecution" as well as "Songs and Tears". These five acts include sixteen scenes. Although the story in these sixteen scenes is not described in as much detail as the original work, it accurately depicts the situation of the two protagonists, Hou Fangyu and Li Xiangjun, encountering by chance, get marrying in great delight, and departing helplessly, thus reflecting the political status of the society at that time. Xu translates the drama in accordance with the layout of original work, and applies different fonts to tell the names of Kunqu melody and the lyrics, etc., which is understandable to the readers at a glance. In translating this drama as he did other classical, Xu aims to enhance Westerners' knowledge of Chinese culture. He intended that by doing such a work, he made some contribution to world harmony.

\section{ANALysis of Foreignization IN PEACH BLOOMS PAINTED WITH BLOOD}

\section{A. The Elements Influencing the Choice of Foreignizing Translation in Peach Blooms Painted with Blood}

The adoption of different translation purposes leads themselves to different translated versions. If we view the interpreter as having two objectives in the translation, we can consider two results. One is to not disturb the author, which is to say, not destroy the expressions of the original author, but to preserve the exotic and artistic features of the original text. This is foreignizing translation. The other intention is to integrate aspects of the target language by using a mode of articulation that the reader can relate to. This is domesticating translation. Which one should be chosen, foreignization or domestication? There is no pat answer. People create different versions in order to express distinct intentions. However, when the translator thinks about what kind of translated version will be created, there are several elements to be considered, affecting the choice of translation strategies and therefore leading to different translated versions. As Guo Jianzhong concludes that the elements are the purpose of translation, the intention of the author, the readership, and the type of text (Guo, 1998). Andre Lefevere proposed two more factors: poetics and ideology. Lefevere writes that these two factors should like this: "basically determine the image of a work of literature as projected by a translation. These two factors are, in the sequence of importance, the translator's ideology (whether he/she willingly embraces it, or whether it is imposed on him/her as a constraint by some form of patronage) and the poetics dominant in 
the receiving literature at the time the translation is made" (Lefevere, 1992). This paper will analyze the influential factors with respect to foreignization. Therefore, given the relationship and hierarchy among these elements with respect to foreignization, these four elements are emphasized, namely, the purpose of translation, the type of text, poetics and ideology. This research focuses on studying the foreignization in Peach Blooms Painted with Blood, so here the relationship of these factors with foreignization attracts more attention.

\section{The Purpose of Translation and Foreignizing Translation}

In the Bible, people work hard to build tower of the Babel so that they can reach heaven. God in retaliation makes the workers speak different languages so they can not cooperate to finish the construction of the Tower. It is true that language can be an obstacle to reach out to others. Statistics show that there are approximately three thousand languages all over the world, among which around ten are widely used. With the development of civilization and technology, more and more countries or regions need to communicate in politics, economy, military, diplomacy, environment, science, and technology, creating a scenario that demands a way to realize it. What is translation? Though not by any means always, it is rendering the meaning of a text into another language in the way that the author intended the text (Newmark, 1988). Therefore, translation is taken as a bridge to people speaking different languages.

Since the translated version of a work is targeted for the nonnative reader, the importance of translators presenting a rich picture of the native culture is obvious. Whether the communication can be successful or not, to some extent, is up to the translators' manipulation. That is, the success of the mission depends on the translator's skill. Their purpose of translation lays a top priority. The Skopos theory, devised by Germen translator Vermeer, proposes that the translator purposes the results on the basis of original text, with the state of mind of the target readers. Among a series of principles, the Skopos theory prioritizes the purpose of the target text in the translation process. Vermeer proposed the concept of translation appointment, that is, the translator decides how to finish the translation task. Translators adopt corresponding translation strategies in accordance with distinct translation purposes. As for the different purposes, translators will employ different translating strategies and methods. In the preface of Peach Blooms Painted with Blood, $\mathrm{Xu}$ Yuanchong said that translating the drama into English can increase the Westerners' knowledge of Chinese culture, and also make a contribution to build a harmonious world (Xu, 2012). Since $\mathrm{Xu}$ Yuanchong aims to introduce Chinese culture to foreigners, it is inevitable that he keeps the original form of the culture and language. That is what the foreignizing translation method lays particular emphasis on. It is necessary to employ it during translation.

\section{The Type of Text and Foreignizing Translation}

Peter Newmark classified text into three types: expressive text, such as authoritative statements, autobiography, essays and so on; informative text, for example, textbooks, articles in newspapers or conference agenda, and vocative text which contains instructions, publicity, persuasive writing and so on. Different types of text require different translation strategies for their functions and language styles are very distinct. For example, drama should be taken as an expressive text. Whether studied and translated as a literary text or as a libretto text for performance affects the choice of translation strategy. In Peter Newmark's view, no matter the purpose of translating a great play, the translator should always assume the latter as his main purpose and he should explain to readers and scholars only in his footnote. From another perspective, one of the functions of theatre is not only to operate on levels other than strictly the linguistics, but also the role of the audience implying a crowd of people, which is to say not the relationship between the sole reader and the text. Susan Bassnett drew the following conclusion by analyzing the translation of Philips and Harrison:

A central consideration of the theatre translator must therefore be the performance aspect of the text and its relationship with an audience, and this seems to me not only to justify modifications of the kind made by Philips or Harrison to Racine's original text, but to suggest that the translator must take into account the function of the text as an element for or of performance. (Bassnett, 2004)

In this case, with the intent of audience enjoyment and engagement, perhaps some explanation to the original content might be embedded in the target text. That is to say, when the translator employs the foreignizing method, some information may be explained through the domestication or adaptation.

Peach Blooms Painted with Blood is translated by Xu Yuanchong as a libretto. Considering the type of the text and the distinct cultures between China and Western countries, the translator uses parentheses, different types of calligraphy, and font size to mark whose words they belong to, which is quite obvious in Xu's translated version. For example.

【滴溜子】双亲在, 双亲在, 信音未准; 烽烟起, 烽烟起, 梓桑半损。...... (末) 不必着慌, 小弟倒有 个算计。 ....... Xu, 2012)

(Singing to the tune of Dripping Drop by Drop)

I have not heard a word/From my family dear,/From my family dear./When beacon fire/Runs higher and higher,/The state is devastated far and near,/Far and near,....../Yang: Do not worry. I think there is a way for you....... (Xu, 2012)

Dripping Drop by Drop is the tune name, so the translator uses parentheses, and the bold and italic fonts to mark it. “双亲在, 双亲在, 信音未准; 烽烟起, 烽烟起, 梓桑半损。” is the content of the tune, “Do not worry. I think there is a way for you." is spoken by Yang Longyou. So the translator uses different font size to differentiate. 
Ideology is a set of beliefs, especially held by a particular group, that influence the way people behave. It always has an indirect effect on the selection of translation strategy through patronage. When considering the target reader, "translations can be potentially threatening precisely because they confront the receiving culture with another, different way of looking at life and society, a way that can be seen as potentially subversive, and must therefore be kept out" (Lefevere, 1992). As Lefevere sees it, "the ideological components act as a constraint on the choice and development of both form and subject matter. Needless to say, 'ideology' is taken here in a sense not limited to the political convention and belief which orders our actions" (Lefevere, 2010). If the author's or translator's work is not coordinated with consumer's ideology, the patron or press may refuse to publish it. Hence, in order to achieve publication, the writer or translator has to abide by the accepted ideology of the target reader which is bound to affect the selection of translation strategy- literal translation or free translation, domestication or foreignization, and the like.

Foreignizing translation maintains the concept of resisting the transfer of the other ideology into the Western culture while at the same time not allowing the dominant culture to alter the original. It is indeed a big challenge to publish in the Western world. That is one of the reasons why, in 1990, the publication and distribution of translations from other languages into English was only $2.4 \%$ in Britain while that takes up 2.96\% in America. However, when Xu Yuanchong determined to do something about promoting Eastern culture, perhaps ideology was a consideration for him when he considers how to translate the work. Finally his patriotism and his original intention of promulgating Eastern culture outweighed the economic considerations. So he persevered to accomplish it. It is fortunate and gratifying that his dream has gradually realized and he becomes the first Chinese translator whose works are published by the Penguin Press.

\section{Poetics and Foreignizing Translation}

What is poetics? The following two scholars have given the similar definitions. In Andre Lefevere's opinion, “A poetics can be said to consist of two components: one is an inventory of literary devices, genres, motifs, prototypical characters and situations, and symbols; and the other a concept of what the role of literature is, or should be, in the social system as a whole (Lefevere, 2010). And as Baker (2004) sees it, "Derived from Aristotle's poetics, the 'poetics of translation' refers to the inventory of genres, themes, and literary devices that comprise any literary system. In translation studies, the term also refers to the role a literary system plays within the larger social system and/or how it interacts with other (foreign) literary or semiotic sign systems (p. 167).

In the first place, from these two definitions we can appreciate that the translator's poetics may borrow a series of literary elements from the original culture or language which do not exist or are different from those in the target culture or languages. One mission of foreignizing translation is to try to incorporate the original devices of culture or language into the target culture or language. As for the translation of Kunqu Opera Peach Blooms Painted with Blood, foreignizing translation can help the translator remain the authentic drama and dedicate to the readers. Meanwhile, through the input of this translated version, the cultures of English-speaking countries are expanded for it is distinct from their native drama. Some translators may adapt the target text during translation while others insist on trying to deliver the original form of the work as much as possible so as to illustrate qualities of their civilization to better inform the target one. Which strategy will be chosen is up to the translator. However, it must be admitted that, just as Lefevere remarks, "The compromises translators find between the poetics of the original and the poetics of their culture provide fascinating insights into the process of acculturation and incontrovertible evidence of the extent of the power of a given poetics" (Lefevere, 1992, p.26). Obviously, foreignization plays an important role in this process.

In the second place, from the latter part of each definition quoted above, it can be seen that poetics is influential in the selection of themes; that is, it must be relevant to the social system if the translator desires to have his work noticed. Currently, Western culture is more popular than that of the Eastern. So the choice of the theme or the work to be translated is a kind of resistance to the dominant culture, which also embodies the essence of foreignization.

\section{B. Case Study of Foreignizing Translation in the Cultural Context of Peach Blooms Painted with Blood}

\section{The Cognition and Classifications of Cultural Context}

In the process of translation, though the advantages of the translated language need to be amplified under many situations, sometimes the merits of the original language should be shown, which, to some extent, can reserve the charm of the original text, and realize the function of literature translation. To exert the merits of original language, foreignizing translation method has always been used by translators. Critics of domestic translation have identified Xu Yuanchong as a representative of the school of domestication, and have singled out for criticism (Zhang, 2006). However, "Language is a part of culture and therefore translating from one language into another cannot be done satisfactorily without adequate knowledge of the two cultures involved" (Ma, 2003, p. 75). It has already been realized that "biculturalism is even more important than bilingualism, since words only have meanings in terms of the cultures in which they function. Dictionaries and encyclopedias are an important source of strategic cultural information, but they can never take the place of personal involvement in a foreign society"(Nida, 2004, p. 110). Readers comprehend the content completely when they consider it within a certain context. The first anthropologist who was aware that language could only be understood in a context of culture was Bronislaw Malinowski. "Context began to receive more attention in 1993 when the American linguist Leonard Bloomfield published Language" (Katan, 2001, p. 73). Moreso, another anthropologist, Spair, was sure that "not only the importance of the social background but that future language studies would turn to a "concept of culture"” (Katan, 
2001, p. 73).

Many scholars have defined or classified cultural context. For instance, Nida has always divided cultural context into five categories: ecological cultural context, linguistic cultural context, material cultural context, religious cultural context, and social cultural context. Clair Kramsch deems that cultural context should include "tribal economics, social organizations, kin patterns, fertility rites, seasonal rhythms, concepts of time and space" (Kramsch, 2000, p. 4). Qi Yucun identifies that cultural context comprises three ingredients: 1) material culture. The various man-made material objects are typical in this group; 2) culture of systems and conventions, that is, the social norms and principles; 3) and spiritual culture, i.e., the mode and product generated through mental activities of human beings. Combined with the translated version Peach Blooms Painted with Blood, the cases of foreignizing translation will be studied from the perspectives of linguistic cultural context, religious cultural context, and social cultural context as follows.

\section{Case Analysis on Foreignizing Translation in Certain Cultural Contexts}

\section{a. Foreignizing Translation in the Linguistic Cultural Context}

Both Chinese and English are languages with long histories and have accumulated a number of cultural connotations. Different people from different regions have different life styles, different thinking patterns and habits. All of these will cause distinct thinking patterns, which get in the way of understanding works of other cultures. In the author's opinion, linguistic culture focuses on the genre of the text, the constituents of the text, idioms, proverbs, allusions and so on. The idioms, proverbs and allusions often express their significances through figures of speech which are always related to culture. In this part, the constituent parts of the text and allusions are chosen for analysis.

Traditional Chinese drama, especially Kunqu Opera, is quite different from drama in Western countries. If you have ever read any Western drama, you would have found that the form is very different and there are some tune names which control the tune of the episode. For example, in comparing G. B. Shaw's Major Barbara and Peach Blooms Painted with Blood, the differences are very obvious. Upon reading Xu's translation, different sizes of words and some boldfaced letters are in the drama. Singing, speaking, acting and acrobatic fighting are four kinds of artistic means in drama performance and they are what the different sizes of words and boldfaced letters refer to. There are thousands of tune names in Kunqu Opera, in which every tune name holds a type of tune and they cannot be used at random. In the following, some instances will be given.

Example 1

【渔灯儿】闹端阳，正纷纭...... (Xu, 2012, p. 202)

(Singing to the tune of Fisherman's Lantern):/On the Dragon Boat Day/ We see all on display...... (Xu, 2012, p. 84)

Example 2

【沉醉东风】记得一雬时娇歌兴扫, 半夜里浓雨情抛; .......(Xu, 2012, p. 214)

(Singing to the tune of Intoxicated in the East Wind) I still remember songs no longer sung in my bower,/Your Example 3

midnight love brings no more fresh shower/ For my thirsty flower...... (Xu, 2012, p. 101)

【懒画眉】为甚的玉真重溯武陵源，也只为水点花飞在眼前.......(Xu, 2012, p. 230)

(Singing with fan in hand to the tune of Idly Penciled Eyebrows) Why should the beauty come back where peach petals fly, /For water sprinkled on the flowers before the eye?...... (Xu, 2012, p. 125-126)

Here, Fisherman's Lantern, Intoxicated in the East Wind, Idly Penciled Eyebrow are randomly selected from Peach Bloom Painted with Blood. All of them are called tune names in traditional Chinese drama. In the translated works of Chen Meilin and Shi Junshan, the translators omit this part, while Xu Yuanchong respects the original culture and transfers it into the translation adding to the strangeness.

Allusion is an attribute of every language and culture which have been generated through the ages. Every allusion has the profound cultural connotation and rich national colors. Since Britain and China have experienced thousands of years, they have unique and vivid metaphorical devices to depict concrete or abstract concepts, such as entities, events, emotions and so on. Sometimes these concepts are similar but sometimes they are not. Following are several examples of gaps in expressed allusions:

Example 4

......这当垆红袖, 谁最温柔, 拉与相如消受。（Xu, 2012, p. 154）

......Who will enjoy the pure delight/Of the rosy-sleeved beauty fair and bright? (Xu, 2012, p. 17)

In this example, there are two characters in the line, in which there is one named Xiangru who is obviously Sima Xiangru. And “当垆红袖” implies Zhuo Wenjun who is Sima Xiangru's lover. Sima Xiangru is a famous scholar in Han Dynasty (about $2^{\text {nd }}$ century B.C.). In a banquet, Sima Xiangru fell in love with Zhuo Wenjun without her father's permission. And then they eloped to Chengdu. Here, this sentence is used to allude to Hou Fangyu and Li Xiangjun. Zhuo Wenjun loved Xiangru very much that she gave up a rich and comfortable life at home, and went to Chengdu with Sima Xiangru. The latter was so poor that Zhuo Wenjun had to sell wine to make ends meet. Using this allusion to describe Hou and Li, make allusion to a happy life. Xu refined and translated 当垆红袖 as “the rosy-sleeves beauty", rather than a foreignizing translation. On the one hand, he kept the original image and transferred the information in the source culture 
in order to make readers understand the implication of the images. This fully demonstrates the advantage of using this allusion in the original text. On the other hand, the way he opted to express the protagonists' emotion is implicit, which is contrary to Western device. So, we can say that to Westerners, this is a creative way to show feelings. Although this may be an obstacle for a foreign audience to comprehend its connotation at the first time, everyone likes beauty. It enlightens them to the new image of beauty, encouraging them to explore the experience. During this process, the audience will gradually understand tacitly and the strangeness at the same time evaporates.

Example 5

……留着他燕子楼中昼闭门, 怎教学改嫁的卓文君。（Xu, 2012, p. 204）

She shuts herself up in the Swallow's Tower. / Why with another lover will she stay? (Xu, 2012, p. 86)

The place where Li Xiangjun lived in is the warm green bower. Kong Shangren, expressed 燕子楼, implies her dwelling. 燕子楼 is the building of Zhang Jianfeng, a Marshal of Tang Dynasty, built for his concubine Guan Panpan, a famous courtesan in Xuzhou. After Zhang died, Guan Panpan insisted on staying in the building and lived in widowhood for him. Xu Yuanchong translated the name as "the Swallow Tower", by which he brought the special cultural element into Western culture. This is a strange place for the foreign readers, but by following the story of the building, they can gain a comprehension of this connotation.

What's more, there are many cases like 白头吟 “song of white hair” implying Sima Xiangru loved others after he married Zhuo Wenjun., 初教瘦马 “begins to drill horses bare”, horses refers to courtesan according to the custom of Yangzhou city of China, 天子 "the son under the sky" referring to the emperor in ancient China and all that. Nida had ever said that all languages have the potential for outstanding aesthetic expression. Nowadays, people live in a diverse world, so everybody should respect other cultures and then reap the benefits of a harmonious world. Translators have the essential role of bridging different cultures. Linguistic culture is a valuable treasure among cultures, and can be preserved by foreignization translation.

\section{b. Foreignizing Translation in the Socio-Cultural Context}

Socio-cultural context is the social cultural pattern that language lives by, which involves ideology, ethnological psychology, thinking patterns, customs and habits, along with universal ethical principle, etc. Before translating, what the translators should possess the necessary knowledge relating to the history and society between both the source text and the target text. Make the discrepancy of the social cultural context between both languages clear and the translation can be much more authentic and perfect. Here, the focus is on customs and habits to illustrate the use of foreignizing translation in Peach Blooms Painted with Blood.

Example 6

【锦缠道】望平康, 凤城东、千门绿杨。一路紫丝缰, 引游郎, 谁家乳燕双双。（Xu, 2012, p. 146）

(Singing to the tune of Silk-Paved Way) : I look up and down/ East of Phoenix Town, / from door to door stand willow trees./ I flip my violet whip/ All the way in my trip,/ Swallows in pair fly in the breeze. Xu, 2012, p. 6)

"Feng cheng" in the drama refers to Nanjing, the capital of the Ming Dynasty. Here, Xu uses the foreignizing translation method to translate it into "Phoenix Town", not revealing any information about it to the readers. However, some clues indeed exist between the lines. Firstly, "from door to door" implies that many people live here and it is a prosperous place. Secondly, it is a very important point that both the Chinese dragon and phoenix are the totems reflecting Chinese characteristics. Therefore, phoenix, together with Loong (Chinese dragon), always used to describe things related to the royal family in Chinese culture, which is taboo for common people. In the feudal society of China, if a common person or the official wears a yellow robe on which is embroidered the pictures of Loong, he will be regarded as traitorous and then be executed when found. Since patriarchalism prevailed in China in feudal period, most references are males. Women except for the emperor's wives were forbidden to use phoenix symbols. Through this analysis, it is not difficult to assume Phoenix Town is the capital Nanjing. In order to retain the original culture and give some exotic experience to foreign readers, Phoenix Town is an appropriate translation. Shi Junshan translates it as "the ancient palace", which is easy to understand but deprives the readers of the original culture. In a word, Xu's translation meets the standard of foreignization.

Example 7

......请老爷同到洞房，唤他出来，好饮扶头卯酒。（Xu, 2012,p. 160）

.......Would you please go to their nuptial chamber and drink their wedding cup together with them? (Xu, 2012, p. 26)

Example 8

.....我立志守节, 岂在温饱。忍寒饥, 绝不下这翠楼梯。(Xu, 2012, p. 211)

......I am determined to be true to Master Hou. How could I care for food and dress? /It is nor hunger nor cold for which I care. / I am determined not to go there. (Xu, 2012, p. 97)

These two examples are related to the wedding customs in China, ancient China in particular. It is known to all that the Western wedding protocol is not as complex as that in China. The situation in the former example is Yang Longyou, one of the match-makers of Hou Fangyu and Li Xiangjun, visited the newlyweds on the morning of the first day after their wedding ceremony. There is a custom that newlyweds need to drink some wine on the morning of the second day. 
What's more, Confucian values and moral system have a great influence on Chinese culture. In accordance with Confucianism, the wife should submit herself to her husband unconditionally. Attitudes towards married couples are quite reserved and conservative. In ancient China, for example, if the husband gets lost or dies, the wife is not allowed to remarry. In the latter example, Hou Fangyu has been gone for three years, and Ruan Dacheng asked Li Xiangjun to marry another official, Tian Yang, despite her resistance so as to get revenge on her. Xu adopts "determined" and "nor hunger nor cold for which I care" to embody Li Xiangjun's determination to wait for her husband. Both of these two cases are perplexing for foreign readers. In Western countries, people take individualism seriously. They find it inconceivable that one person loses freedom to another person. Xu Yuanchong, unlike some translators who try their best to adapt the source text to cater for readers, breaks the common principle of Western countries and gives new insights into another life style and culture.

Foreignization translation can help maintain the source culture during translation. Moreover, texts and their socio-cultural context are interdependent on each other. Without the background, readers cannot catch the exact meanings. Translation, especially literature translation, should be comprehended in the socio-cultural context, as well as explored in its connotations. Only in this way, can one appreciate the cultural aspects of translation in the target language. It is a good choice to understand the foreignizing translation version on the certain context.

\section{c. Foreignizing Translation in the Religious Cultural Context}

Religious culture has a special place in society and is an important component of human culture. Almost every nation has its religions beheld. Religious culture includes a people's belief, religious system, religious works and rules (Meng, 2012). Religious culture has distinctive national features and different religions reflect different types of culture. As we all know, the Bible and the myths in Greece and Rome are the two sources of Western culture, while Buddhism and Taoism are the two religions having the greatest influence on Chinese culture. Buddhism is marked implicitly or explicitly in Chinese ancient drama with respect to genre and implication. The theorist Zhu Quan of the Ming Dynasty classified Yuanqu opera into twelve kinds among which two are types mainly related to Taoism. (Xu, 2012) Thus, when translating Chinese traditional drama, religious culture must be considered. Next are some examples in religious cultural context: “是 他天公不费买花钱, 则咱心上人有啼红怨。”(Xu, 2012, p. 230) “To buy flowers Heaven need not pay, / It cares not for my bloody tears shed on the way,”(Xu, 2012, p. 126) “或者天恩见怜, 放奴出宫, ” (Xu, 2012, p. 231) “I only wish Heaven would set me free.”(Xu, 2012, p. 127) “竟是长斋绣佛女尼身，怕落了风尘。”（Xu, 2012, p. 204）“Like a Buddhist careless of everything.” (Xu, 2012, p. 87) “阿弥陀佛。” (Xu, 2012, p. 148) “Buddha is blessed!” (Xu, 2012, p. 10)

From the above four examples, it can be seen that Buddhism has marked influence on the writing and translating of this work, Peach Blooms Painted with Blood. In the first two examples, 天公 and 天 are translated as "Heaven", not the equivalent word "God" in English (in some way the two words are equivalent), as Buddhism is believed by Chinese. Li Xiangjun was selected as a songstress and entered the imperial palace. She missed Hou Fangyu so much that she prayed to Heaven for a chance to be free again, showing that she believed in Heaven implicitly. This is applicable to most Chinese. This is applicable in the next two examples. Perhaps, 佛女尼身 is similar to "nun” or "sister" in English, as nuns of the Roman Catholic and Eastern Orthodox churches have some identical behaviors. Xu translates Buddhist as a person whose religion is Buddhism. 阿弥陀佛 is an expression the disciples used to pray for shelter. While in English-speaking countries they may say "God bless you!" or something like that. American president Barack Obama said "May God bless the United States of America!" in his first inaugural speech, which is a good case in point. However, if the expression in the drama is translated "God" not "Buddha", although much easier for the audience to understand, makes the followers seem to be Christians not Buddhists. It is not faithful to the original text and does not respect the source culture. From these examples, we can see that Xu maintains the original religious color through foreignization. The images containing cultural connotation should be and only could be translated through foreignization to keep the Chinese cultural elements, to realize the cultural communication, not to cater to the target culture (Zhang \& Gao, 2020).

\section{CONCLUSION}

Different contexts and cultures' atmospheres lead to different literary and cultural interpretations of social phenomenon, or the same part of the literary work. They will restrict the choice of works, the translation standards, and methods. After selecting the translated works, the translators will choose translation methods in accordance with their translation purposes. If they want to introduce an exotic culture, they will choose foreignization; if they intend to inspire the readers or audience, they will choose domestication. In Peach Blooms Painted with Blood, the style, drama, indicates performance before an audience. Xu Yuanchong translates according to the principle that the readers or the audience can get an approximate comprehension of the material. However, after analysis, it can be shown that, as Xu said, transferring some Chinese cultural information to Western culture and gives foreigners a new insight to Chinese culture, especially ancient culture. From the illustration above, we can know that in the linguistic, social, and religious cultural contexts of Chinese, the objects have different connotations from those in relevant Western cultural contexts, which can affect the translation. Xu Yuanchong employs the foreignizing translation method and shows it to the readers and audience, which is a good way to spread Chinese culture and improve foreigners' cognition of it. The gap between two cultures cannot be 
ignored, and those who tend to read or enjoy the foreign works are already prepared to accept exotic cultures. Translators should not omit or adapt the cultural information in the source text only to cater to readers. Foreignization needs to be considered while delivering the original information to the readers.

\section{REFERENCES}

[1] Baker, M. (2004). Routledge Encyclopedia of Translation Studies. Shanghai Foreign Language Education Press.

[2] Bassnett, S. (2004). Translation Studies (3rd ed.). Shanghai Foreign Language Education Press.

[3] Guo, J. Z. (1998). Fan yi zhong de wen hua yin su: yi hua yu gui hua [Approaches to cultures involved in translation: Adaptation and Alienation]. Journal of Foreign Languages, 2, 13-20.

[4] Katan, D. (2001). Translating Cultures- An Introduction for Translators, Interpreters and Mediators. Shanghai Foreign Language Education Press.

[5] Kramsch, C. (2000). Language and Culture. Shanghai Foreign Language Education Press.

[6] Lefevere, A. (Ed.). (1992). Translation History Culture: A Sourcebook. Routledge.

[7] Lefevere, A. (2010). Translation, Rewriting and the Manipulation of Literary Fame. Shanghai Foreign Language Education Press.

[8] Ma, H. J. (2003). A Study on Nida's Translation Theory. Foreign Language Teaching and Research Press.

[9] Meng, W. G. (2012). A Study of Drama Translation. Zhejiang University Press.

[10] Newmark, P. (1988). A Textbook of Translation. Prentice Hall International Ltd..

[11] Nida, E. (2004). Language, Culture, and Translating. Shanghai Foreign Language Education Press.

[12] Venuti, L. (2004). The Translator's Invisibility-A History of Translation. Shanghai Foreign Language Education Press.

[13] Xu, Y. C. \& Xu, F. M. (2012). Peach Blooms Painted with Blood. China Intercontinental Press.

[14] Zhang, Y. \& Gao, M. L. (2020). Zhong guo gu dian shi ci yi xiang fan yi ce lve-jian tan zhong guo wen hua dui wai chuan bo [Strategy in Translating Imagery in Chinese Classical Poetry-Also A Talk on Dissemination of Chinese Culture in Western Countries]. Forward Position, 1, 116-123.

[15] Zhang, Z. Z. (2006). Xu Yuanchong and the Art of Translation. Hubei Education Press.

Shaohui Lu has a Bachelor degree in English Education in 2010, an MA in English Language and Literature from Guizhou University in 2014. Currently, she is a Lecturer of School of Foreign Language, Zunyi Medical University. Her research areas of interest include Translation and culture study, English teaching and learning. 